\title{
Astrocytic Tissue Inhibitor of Metalloproteinase-1 (TIMP-1) Promotes Oligodendrocyte Differentiation and Enhances CNS Myelination
}

\author{
Craig S. Moore, ${ }^{1}$ Richard Milner, ${ }^{2}$ Akiko Nishiyama, ${ }^{4}$ Ricardo F. Frausto, ${ }^{3}$ David R. Serwanski, ${ }^{4}$ Roberto R. Pagarigan, ${ }^{1}$ \\ J. Lindsay Whitton, ${ }^{3}$ Robert H. Miller, ${ }^{5}$ and Stephen J. Crocker ${ }^{1}$ \\ ${ }^{1}$ Department of Neuroscience, University of Connecticut Health Center, Farmington, Connecticut 06030, Departments of ${ }^{2}$ Molecular and Experimental \\ Medicine, and ${ }^{3}$ Immunology and Microbial Science, The Scripps Research Institute, La Jolla, California 92037, ${ }^{4}$ Department of Physiology and \\ Neurobiology, University of Connecticut, Storrs, Connecticut 06269, and ${ }^{5}$ Department of Neurosciences, Case Western Reserve University School of \\ Medicine, Cleveland, Ohio 44106
}

Tissue inhibitor of metalloproteinase-1 (TIMP-1) is an extracellular protein and endogenous regulator of matrix metalloproteinases (MMPs) secreted by astrocytes in response to CNS myelin injury. We have previously reported that adult TIMP-1 knock-out (K0) mice exhibit poor myelin repair following demyelinating injury. This observation led us to hypothesize a role for TIMP-1 in oligodendrogenesis and CNS myelination. Herein, we demonstrate that compact myelin formation is significantly delayed in TIMP-1 KO mice, a situation that coincided with dramatically reduced numbers of white matter astrocytes in the developing CNS. Analysis of differentiation in CNS progenitor cells (neurosphere) cultures from TIMP-1 KO mice revealed a specific deficit of NG2 ${ }^{+}$oligodendrocyte progenitor cells. Application of recombinant murine TIMP-1 (rmTIMP-1) to TIMP-1 KO neurosphere cultures evoked a dose-dependent increase in NG2 ${ }^{+}$ cell numbers, while treatment with GM6001, a potent broad-spectrum MMP inhibitor did not. Similarly, administration of rmTIMP-1 to A2B5 ${ }^{+}$immunopanned oligodendrocyte progenitors significantly increased the number of differentiated $01^{+}$oligodendrocytes, while antisera to TIMP-1 reduced oligodendrocyte numbers. We also determined that $\mathrm{A} 2 \mathrm{~B} 5{ }^{+}$oligodendrocyte progenitors grown in conditioned media derived from TIMP-1 KO primary glial cultures resulted in reduced differentiation of mature $01^{+}$oligodendrocytes. Finally, we report that addition of rmTIMP-1 to primary glial cultures resulted in a dose-dependent proliferative response of astrocytes. Together, these findings describe a previously uncharacterized role for TIMP-1 in the regulation of oligodendrocytes and astrocytes during development and provide a novel function for TIMP-1 on myelination in the developing CNS.

\section{Introduction}

Tissue inhibitors of metalloproteinases (TIMPs) are well recognized endogenous regulators of the matrix metalloproteinase (MMP) family of extracellular proteases (Crocker et al., 2004). TIMP-1 is a $29 \mathrm{kDa}$ secreted protein first identified as a collagenase inhibiting factor in serum (Woolley et al., 1975). Expression of TIMP-1 in the CNS is significantly higher during postnatal development compared with the adult, where it is very low to undetectable (Young et al., 2002a; Ulrich et al., 2005). In response to inflammatory myelin injury, TIMP-1 is robustly induced within the CNS (Pagenstecher et al., 1998; Crocker et al., 2006b;

\footnotetext{
Received Oct. 18, 2010; revised March 3, 2011; accepted March 8, 2011.

Author contributions: C.S.M., R.M., J.L.W., R.H.M., and S.J.C. designed research; C.S.M., R.M., A.N., R.F., D.R.S., R.R.P., R.H.M., and S.J.C. performed research; A.N. and R.H.M. contributed unpublished reagents/analytic tools; C.S.M., R.M., R.F., D.R.S., R.R.P., J.L.W., R.H.M., and S.J.C. analyzed data; C.S.M. and S.J.C. wrote the paper.

This work was supported in part by a Career Transition Fellowship from the National Multiple Sclerosis Society (NMSS) (to S.J.C.); start-up funds from the University of Connecticut Health Center (to S.J.C.); an NMSS Harry Weaver Fellowship (R.M.); and National Institutes of Health Grants Al-27028 (to J.L.W.) and NS030800 (to R.H.M.). We gratefully acknowledge Sarah Maclsaac for technical assistance.

The authors declare no competing financial interests.

Correspondence should be addressed to Stephen J. Crocker at the above address. E-mail: crocker@uchc.edu. DOI:10.1523/JNEUROSCI.5474-10.2011

Copyright $\odot 2011$ the authors $\quad 0270-6474 / 11 / 316247-08 \$ 15.00 / 0$
}

Ulrich et al., 2006), where it is predominantly expressed by astrocytes surrounding white matter lesions (Pagenstecher et al., 1998; Nygårdas and Hinkkanen, 2002). These observations lend support for TIMP-1 as an endogenous factor expressed to mitigate MMP activities during neuroinflammation (Pagenstecher et al., 1998; Althoff et al., 2010). However, accumulating evidence also indicates that the biological actions of TIMPs are not solely limited to MMP inhibition (Chesler et al., 1995; Crocker et al., 2004; Stetler-Stevenson, 2008). For example, TIMP-1 has been shown to have growth factor activity (Murate et al., 1993), and antiapoptotic potential (Jourquin et al., 2005), functions that may be mediated through ligand-receptor interactions (Jung et al., 2006; Tsagaraki et al., 2010). Hence, MMP-independent actions of TIMP-1 may also contribute to its biological effects in the developing and injured CNS.

We have previously reported that TIMP-1-deficient [i.e., TIMP-1 knock-out (KO)] mice exhibit poor myelin recovery in experimental autoimmune encephalomyelitis (EAE), a model of T-cell-mediated myelin injury (Crocker et al., 2006b). In TIMP-1 $\mathrm{KO}$ mice, there was also a dramatic reduction in astrogliosis during EAE (Crocker et al., 2006b). These findings prompted us to reconsider the expression of TIMP-1 by astrocytes, and led us to 
hypothesize a temporal and spatial relationship between astrocytic TIMP-1 and myelination. Herein, we report that early postnatal myelination of the CNS is markedly delayed in TIMP-1 KO mice and demonstrate that TIMP-1 promotes both astrocyte proliferation and oligodendrocyte progenitor cell (OPC) differentiation in a dose-dependent and MMP-independent manner. Results from this study identify TIMP-1 as a novel astrocytic-derived factor that can directly influence CNS myelination.

\section{Materials and Methods}

Mice. All procedures were approved by the Institutional Animal Care and Use Committee at the University of Connecticut Health Center (Farmington, CT). TIMP-1 KO mice (Lee et al., 2005) were backcrossed onto a C57BL/6 background for $>13$ successive generations, bred as a homozygous line (Crocker et al., 2006b), and used in this study. Wild-type (WT) C57BL/6 mice were bred and used as controls for all experiments (Jackson Laboratories). All mice examined in these experiments that were postnatal day 7 (P7) or older were male.

Primary mixed glial and neurosphere cultures. Cells were prepared from P0-P2 wild-type C57BL/6 or TIMP-1 KO mouse pups, as previously described (Crocker et al., 2006a, 2008). Mixed glial cultures were grown in DMEM containing $10 \%$ FBS [with penicillin $(50 \mathrm{U} / \mathrm{ml})$ and streptomycin $(50 \mu \mathrm{g} / \mathrm{ml})]$ and plated onto laminin-coated coverglass for immunocyto-

chemistry in 24 well plates and fixed with $4 \%$ paraformaldehyde, as previously described (Crocker et al., 2008). Neurosphere cultures were grown in serum-free DMEM:F12 [containing penicillin $(50 \mathrm{U} / \mathrm{ml})$, streptomycin $(50 \mu \mathrm{g} / \mathrm{ml})$, B27 supplement, epidermal growth factor (10 ng/ $\mathrm{ml}$ ), fibroblast growth factor-2 (FGF-2; $20 \mathrm{ng} / \mathrm{ml})$, and heparin $(2 \mu \mathrm{g} /$ $\mathrm{ml})$ ]. After 1 week in culture, neurospheres were plated onto $12 \mathrm{~mm}$ laminin or fibronectin-coated coverslips in wells of a 24 well culture dish and differentiated into glial and neuronal populations for $7 \mathrm{~d}$ [DMEM containing 1\% FBS and N1 supplement (Sigma)] either with or without recombinant murine TIMP-1 (1-100 ng/ml, R\&D Systems) or the panMMP inhibitor GM6001 (125 $\mu \mathrm{M}$, Calbiochem).

$\mathrm{A} 2 \mathrm{B5}^{+}$oligodendrocyte progenitor cells. Immunopanned OPCs were prepared from neonatal rats as previously described (Barres et al., 1992; Fok-Seang and Miller, 1992; Noll and Miller, 1994). All experiments were performed in a double-blind fashion with coded samples provided for treatment of cell cultures and decoded only following data collection. For experiments using anti-TIMP-1 (0.6 $\mu \mathrm{g} / \mathrm{ml}, \mathrm{R} \& D$ Systems $)$, control IgG ( $1 \mu \mathrm{g} / \mathrm{ml}$, Sigma), recombinant murine TIMP-1 (10 ng/ml, R\&D Systems) or vehicle (TCNB buffer), A2B5 ${ }^{+}$cultures were treated overnight, fixed, and stained for $\mathrm{O} 1$ by immunocytochemistry. In all experiments using glial conditioned media $(\mathrm{GCM}), \mathrm{A} 2 \mathrm{~B} 5{ }^{+}$cultures were maintained in either WT or TIMP-1 KO GCM for 1 week. Cells were then fixed, immunostained for $\mathrm{O} 1$, and quantified. Conditioned media were taken at a time point when mixed glial cultures were $\sim 75 \%$ confluent $(\sim 3-4 \mathrm{~d})$ and stored at $-80^{\circ} \mathrm{C}$. The concentration of TIMP- 1 in WT GCM was determined by ELISA (R\&D Systems). Data are representative of results from a triplicate experiment that was repeated three times. Data are reported as the proportion of control (WT) due to interexperiment variability among independently prepared cultures and the absolute numbers of each cell type between experimental trials.

Immunohistochemistry and image analysis. Spinal cord sections (6-8 $\mu \mathrm{m}$ thick) were collected from P0, P3, P6, P10, P14, and P21 WT and TIMP-1 KO mice, placed into formalin (10\%) fixative, and paraffin em- bedded. Immunohistochemistry was performed, as described previously (Crocker et al., 2006b), using the following antibodies: myelin basic protein (MBP; 1:3000, Millipore), neurofilament M (NeuroM; 1:500, Millipore), NG2 (1:500, Millipore), glial fibrillary acidic protein (GFAP; 1:1000, Dako), A2B5 (ATCC), and O1 (Sigma). All immunostaining was visualized using Alexa-fluorophore-conjugated secondary antisera (1: 500, Invitrogen). All images were acquired using Northern Eclipse software (Empix Imaging) on an Olympus IX71 inverted microscope. All sections used for comparative analyses of NeuroM, MBP, and GFAP used the same reagents and were run in parallel at the same time. Total axon numbers were averaged by counting $\mathrm{NeuroM}^{+}$axons on serial sections ( $n=3$ /animal) from the ventral white matter of spinal cord $(n=$ 3 /group). The percentage of myelinated axons was obtained by dividing the number of concentrically myelinated axons by the total number of axons in each section. Total numbers of $\mathrm{NG}^{+}, \beta 3$-tubulin ${ }^{+}$, and $\mathrm{GFAP}^{+}$were counted in nine arbitrarily set fields of view $(3 \times 3)$ of a 12 $\mathrm{mm}$ coverslip.

Electron microscopy. The vertebral columns from terminally anesthetized P7 WT and TIMP-1 KO mice $(n=4)$ were dissected and processed for electron microscopy (EM) as previously described (Komitova et al., 2009). Ultrathin sections (70-90 nm thick) were cut and put onto 200 mesh copper grids that were visualized with a Tecnai Biotwin $12 \mathrm{kV}$ transmission electron microscope (FEI) and images were processed digitally.

Protein isolation, SDS-PAGE, and Western blotting. Whole spinal cord protein lysates from P7 TIMP-1 KO and WT mice were separated by SDS-PAGE, and Western blotting was performed using anti-GFAP (1: 3000, Dako), proliferating cell nuclear antigen (PCNA; 1:100, Abcam), and procaspase-3 (1:100, Millipore). Equivalent loading was verified by $\beta$-actin (1:20,000, Sigma). Densitometric measurements of all Western blots were performed using ImageJ software (National Institutes of Health).

Bromodeoxyuridine incorporation and terminal second row deoxynucleotidyl transferase-mediated biotinylated UTP nick end labeling assay. Mixed glial cultures were grown on laminin-coated coverslips for $48 \mathrm{~h}$ 
and then treated with either recombinant murine TIMP-1 (rmTIMP-1; $10 \mathrm{ng} / \mathrm{ml})$ or GM6001 (1.25-125 $\mu \mathrm{M})$. For analysis of cell proliferation, bromodeoxyuridine (BrdU; $10 \mu \mathrm{M}$ ) was added to each culture condition for $24 \mathrm{~h}$ before fixation and labeling using 3,3'-diaminobenzidine, according to manufacturer's protocol (BD PharMingen). Parallel experiments were also performed to analyze DNA fragmentation, indicative of programmed cell death, using a TACS 2 TdT Fluorescein In Situ Apoptosis Detection Kit (Trevigen).

Statistical analyses. Data are presented as mean \pm SEM. A one-way ANOVA with Tukey's post hoc tests or unpaired Student's $t$ test was used to determine group differences. For all tests, $p<0.05$ was considered significant.

\section{Results}

Compact myelin formation is delayed in TIMP-1 KO mice

We first examined the temporal expression of TIMP-1 in the spinal cord during early postnatal development by quantitative PCR. Consistent with previous studies (Young et al., 2002b; Ulrich et al., 2005), timp-1 mRNA was expressed at higher levels during the early postnatal period and declined with age (supplemental Fig. 1, available at www.jneurosci.org as supplemental material). These data supported a temporal correlation between increased expression of TIMP-1 during the critical time of CNS myelination (Foran and Peterson, 1992). To explore the effect of TIMP-1 deficiency on developmental CNS myelination, we compared myelination in the spinal cords of WT and TIMP-1 KO mice ranging from $\mathrm{P} 0$ to $\mathrm{P} 21$ in postnatal age. Immunohistochemical analysis of MBP, a major protein component of compact myelin, revealed significantly fewer myelinated axons in P7 TIMP-1 KO mice compared with age-matched WT C57BL/6 mice (Fig. $1 A, B$ ). No differences in the numbers of axons (Neu$\mathrm{roM}^{+}$) or their diameters were noted between TIMP-1 KO and age-matched WT mice (supplemental Fig. 2, available at www. jneurosci.org as supplemental material) (Fig. 1 $A, B$ ), indicating that reduced myelination was not a result of delayed or impaired axonogenesis in TIMP-1 KO mice. Using EM, ultrastructural analysis of myelinated axons in dorsal column of the P7 spinal cord confirmed a 50\% reduction in TIMP-1 KO mice compared with WT mice (Fig. $1 B$ ) $(58.8 \pm 2.4 \%$ in WT vs $29.6 \pm 8.3 \%$ in TIMP-1 KO). Furthermore, these axons had $24.4 \%$ fewer myelin wraps per axon $(9.9 \pm 0.28$ wraps in WT vs $7.4 \pm 0.35$ wraps in TIMP- $1 \mathrm{KO}$ ), and there was a $28 \%$ increase in periaxonal space (Fig. $1 A, B)(0.42 \pm 0.01$ in WT vs $0.54 \pm 0.02$ in TIMP-1 KO). Among the myelinated axons in the TIMP-1 KO mice, myelin also appeared loosely wrapped compared with the tightly myelinated axons of WT mice. These differences were most apparent in the CNS of TIMP-1 KO mice at P7. These differences also resulted in a $7.8 \%$ reduction in the G-ratio of myelinated axons in TIMP-1 KO mice (supplemental Fig. 2, available at www. jneurosci.org as supplemental material $)(0.89 \pm 0.01$ in WT mice vs $0.82 \pm 0.01$ in TIMP- $1 \mathrm{KO}$ mice).

Since TIMP-1 KO mice exhibited a delay in CNS myelination, we next sought to determine whether this phenotype was related to differences in OPC number. Immunohistochemistry for platelet-derived growth factor $\alpha$ receptor (PDGF $\alpha \mathrm{R}$ ) was used to identify OPCs in tissues from TIMP-1 KO and age-matched WT mice. Throughout the CNS white matter (brain and spinal cord) of $\mathrm{P} 7 \mathrm{TIMP}-1 \mathrm{KO}$ mice, a $57 \%$ reduction in the number of PDGF $\alpha \mathrm{R}^{+}$OPCs cells was observed (Fig. 1C; supplemental Fig. 3, available at www.jneurosci.org as supplemental material) (178.7 \pm 14.1 in WT mice vs 78.0 \pm 40.15 in TIMP-1 KO mice). These differences in OPC numbers were not observed at later developmental time points (P14 or P21) (supplemental Fig. 3, available at www.jneurosci.org as supplemental material). This
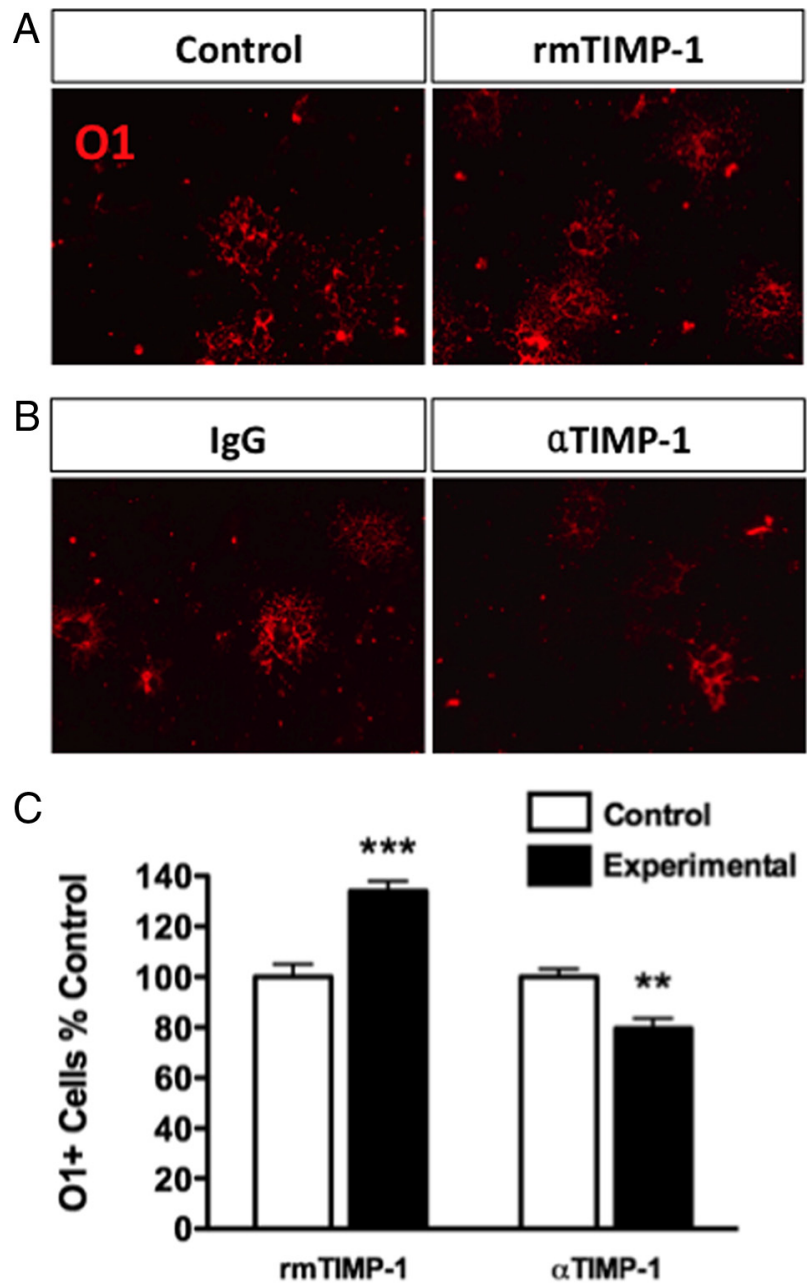

Figure 2. Differentiation of primary $\left(\mathrm{A} 2 \mathrm{~B} 5{ }^{+}\right) \mathrm{OPC}$ cultures into mature $01^{+}$oligodendrocytes can be increased or decreased by adding or blocking TIMP-1, respectively. A, Following a $48 \mathrm{~h}$ treatment with $\mathrm{rmTIMP}-1(10 \mathrm{ng} / \mathrm{ml})$ in purified immunopanned $\mathrm{A} 2 \mathrm{~B} 5{ }^{+}$rat $\mathrm{OPC}$ cultures, increased numbers of mature $\left(01^{+}\right)$oligodendrocytes were observed. Control cultures were also treated for $48 \mathrm{~h}$ in similar volumes, but lacking TIMP-1. ${ }^{* *} p<0.001, t$ test. $\boldsymbol{B}$, Administration of a blocking anti-TIMP-1 antibody $(0.6 \mu \mathrm{g} / \mathrm{ml})$ to immunopanned A2B5 ${ }^{+}$cultures for $48 \mathrm{~h}$ decreased $01^{+}$cell numbers compared with control $\operatorname{lgG}(1 \mu \mathrm{g} / \mathrm{ml})$. ${ }^{* *} p<0.006, t$ test. $C$, All data using $\mathrm{A} 2 \mathrm{~B} 5^{+}$cultures are representative of three independent experiments performed in triplicate using coded samples in a double-blinded fashion. Error bars represent the mean \pm SEM.

decrease in OPC abundance was consistent with the delayed myelination observed in the TIMP-1 KO mice at P7 and suggested that TIMP-1 might influence OPC development and/or differentiation.

\section{OPC differentiation is enhanced by TIMP-1}

To determine whether TIMP-1 could directly influence oligodendrocyte differentiation, we used immunopanned OPC $\left(\mathrm{A} 2 \mathrm{~B} 5^{+}\right)$cultures from neonatal rats. Treatment of $\mathrm{A} 2 \mathrm{~B} 5{ }^{+} \mathrm{OPCs}$ for $48 \mathrm{~h}$ with rmTIMP-1 resulted in a significant increase $(34 \pm$ $0.45 \%)$ in the number of differentiated $\mathrm{O}^{+}$oligodendrocytes when compared with the $\mathrm{A} 2 \mathrm{~B} 5{ }^{+}$cultures treated with vehicle (138 \pm 8 in control, untreated, vs $185 \pm 9$ in rmTIMP- 1 treated cultures; $p<0.001, t$ test vs control) (Fig. $2 \mathrm{~A}$ ). Conversely, in additional sets of $\mathrm{A} 2 \mathrm{~B} 5^{+}$cultures treated for $48 \mathrm{~h}$, administration of a function-blocking antibody to TIMP-1 ( $\alpha$ TIMP-1), but not an IgG isotype-matched control antibody (Crocker et al., 2007), resulted in an $18 \%$ decrease in the number of mature $\mathrm{O}^{+}{ }^{+}$oli- 
godendrocytes (155 \pm 7 in control, untreated vs $125 \pm 8$ in $\alpha$ TIMP- 1 -treated cultures; $p<0.002, t$ test vs control) (Fig. $2 B$ ).

\section{TIMP-1 increases $\mathrm{NG}_{2}{ }^{+} \mathrm{OPC}$ numbers in neurosphere cultures \\ While TIMP-1 significantly increased the} numbers of $\mathrm{O}^{+}$cells in a purified OPC population, we next determined whether the effects of TIMP-1 on early OPCs could be modeled in a heterogeneous cellular environment containing both glia and neurons. TIMP-1 KO and WT neurospheres were grown on fibronectin or laminin, two substrates previously shown to promote growth of early OPCs (Buttery and ffrench-Constant, 1999; Kearns et al., 2003). In this assay, OPCs were identified by immunocytochemical detection of the proteoglycan NG2 (Nishiyama et al., 2009). When cultured on either substrate, $\mathrm{NG}_{2}{ }^{+}$cells were decreased by $\sim 76 \%$ in cultures derived from TIMP-1 KO mice (Fig. $3 A, B)$. These effects were reversed by application of rmTIMP-1 $(1-100 \mathrm{ng} / \mathrm{ml})$, resulting in a dosedependent increase in the numbers of $\mathrm{NG}^{+}$cells $(1 \mathrm{ng} / \mathrm{ml}$, $179.3 \pm 43.1 \%$ increase in $\mathrm{NG}^{+}$cell numbers; $10 \mathrm{ng} / \mathrm{ml}$, $342.3 \pm 74.8 \%$ increase in $\mathrm{NG}^{+}$cell numbers vs untreated TIMP-1 KO neurosphere cultures) (Fig. 3C,D). Treatment with the pan-MMP inhibitor GM6001 did not increase $\mathrm{NG}^{+}$cell numbers in TIMP-1 KO cultures, suggesting that the actions of TIMP-1 were not a result of decreased MMP activity. We also noted that in TIMP-1 KO cultures treated with rmTIMP-1 many $\mathrm{NG}^{+}{ }^{+}$cells had highly branched processes reflecting a more advanced stage of differentiation (Nishiyama et al., 2009) (Fig. 3C, right panels).

\section{Numbers of GFAP ${ }^{+}$astrocytes are decreased in the developing CNS of TIMP-1 KO mice}

We have previously reported that TIMP-1 is produced by astrocytes (Crocker et al., 2006a), and that TIMP-1 KO mice exhibit poor myelin recovery following EAE (Crocker et al., 2006b). EAE pathology in TIMP-1 KO mice was also accompanied by a notable decrease in the numbers of astrocytes in the injured CNS (Crocker et al., 2006b). Since astrocytes play an important role in promoting myelination (Moore et al., 2011), these findings led us to examine whether astrocyte activation differed between TIMP-1 KO and WT mice during early postnatal CNS development. Immunohistochemistry for GFAP, a marker of astrocyte activation, revealed a significant decrease in the density of reactive astrocytes populating the white matter of the spinal cord of TIMP-1 KO mice (Fig. 4). Similar results were also observed throughout the CNS of TIMP-1 KO mice at this same age (supplemental Fig. 4, available at www.jneurosci.org as supplemental material). Western blot analysis of whole spinal cord lysates confirmed a $>50 \%$ reduction in GFAP levels in P7 TIMP-1 KO mice compared with age-matched WT mice (Fig. 4B). To determine whether TIMP-1 could directly act as a mitogen for astrocytes, we administered rmTIMP-1 ( $48 \mathrm{~h})$ to primary glial cultures and counted the numbers of GFAP ${ }^{+}$cells. Using a primary glial culture derived from TIMP-1 KO mice, the addition of rmTIMP-1 $(10 \mathrm{ng} / \mathrm{ml})$, but not the pan-MMP inhibitor GM6001 doubled the number of $\mathrm{GFAP}^{+}$cells after $48 \mathrm{~h}$ (Fig. $\left.5 A, B\right)(108.9 \pm 15.6$ in control, untreated cultures vs $227.3 \pm 24$ in rmTIMP-1-treated cultures). Similarly, application of rmTIMP-1, but not GM6001, also stimulated $\mathrm{GFAP}^{+}$astrocyte proliferation in WT cultures (supplemental Fig. 5, available at www.jneurosci.org as supplemental material $)\left(63.3 \pm 22.3 \mathrm{GFAP}^{+}\right.$cells per field in control, untreated cultures vs $38.78 \pm 3.5$ in GM6001-treated cultures vs $195.8 \pm 57.1$ in rmTIMP-1-treated cultures), although the concentration of TIMP-1 needed was higher $(100 \mathrm{ng} / \mathrm{ml})$, likely because TIMP-1 was constitutively produced in WT cultures (7.5 $\mathrm{ng} / \mathrm{ml})$.

To discriminate whether the known biological effects of TIMP-1 to either prevent cell death (Tan et al., 2003) or stimulate cellular proliferation (Hernández-Guillamon et al., 2009) accounted for the effects of TIMP-1 in our astrocyte cultures, we used BrdU incorporation assays and Western blotting for apoptotic and proliferative markers. A significant increase in the number of $\mathrm{BrdU}^{+}$astrocytes was observed following application of rmTIMP-1 (10 ng/ml) (Fig. $5 C)(58.23 \pm 1.4 \%$ in control, untreated cultures vs $66.7 \pm 1.4 \%$ in rmTIMP-1-treated cultures). Similarly, using Western blotting techniques, an increase in PCNA protein levels, a marker of cell proliferation, was observed in protein lysates from astrocytes treated with $10 \mathrm{ng} / \mathrm{ml}$ rmTIMP-1 (supplemental Fig. 6A, available at www.jneurosci. org as supplemental material). Treatment with TIMP-1 did not stimulate activation of caspase-3 as levels of procaspase-3 levels remained unchanged, arguing against a significant antiapoptotic effect of TIMP-1 in this system (supplemental Fig. $6 \mathrm{~A}$, available at www.jneurosci.org as supplemental material).

\section{Glial conditioned media lacking TIMP-1 produces fewer and less mature OPCs}

To refine our understanding about whether astrocytic TIMP-1 could influence OPC growth and differentiation, we collected conditioned media from TIMP-1 KO or WT primary glial cultures and used this media to culture $\mathrm{A} 2 \mathrm{~B} 5{ }^{+}$-immunopanned OPCs (Baracskay et al., 2007). Upon examination of the numbers of $\mathrm{O}^{+}$oligodendrocytes 1 week later, $\mathrm{A} 2 \mathrm{~B} 5^{+}$cultures grown in 
A

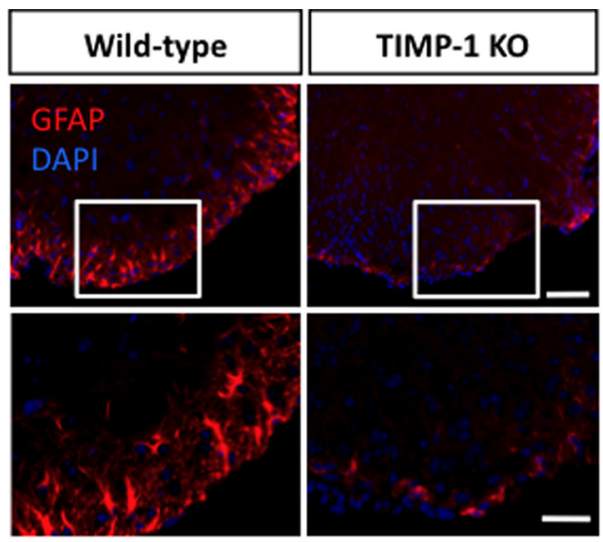

B
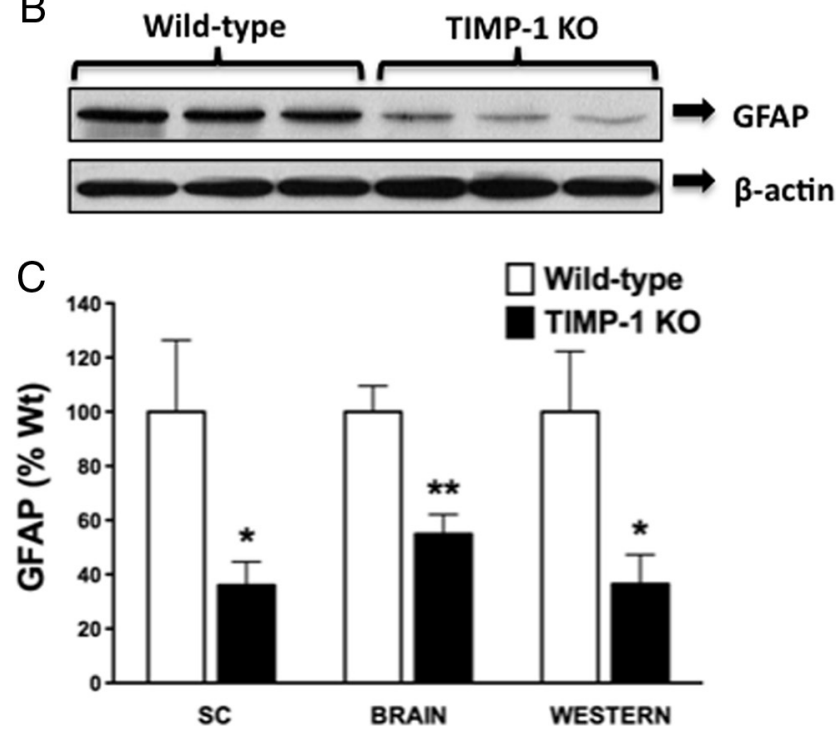

Figure 4. Decreased reactive astrocyte numbers in spinal cords of P7 TIMP-1 K0 mice. A, P7 spinal cord sections immunostained for GFAP revealed a dramatic decrease in the numbers of reactive astrocytes between WT and TIMP-1 KO mice. $\boldsymbol{B}$, Representative Western blot analysis of P7 spinal cord lysates confirmed reduced GFAP expression levels in the spinal cords of TIMP-1 KO mice ( $n=5$ /group). $C$, Integrated pixel density of GFAP in both the spinal cords (SCS) and brains was performed in addition to the densitometry on the Western blot relative to the loading control $\beta$-actin. Scale bar, $200 \mu \mathrm{m}$. ${ }^{*} p<0.05 ;{ }^{* *} p<0.01$. Error bars represent the mean \pm SEM. DAPI, 4,6-Diamidino-2-phenylindole.

WT GCM readily differentiated into $\mathrm{O} 1^{+}$oligodendrocytes with broad and expansive myelin sheets (Fig. 6A,B). In contrast, $\mathrm{A} 2 \mathrm{~B}^{+}{ }^{+}$cultures grown in TIMP-1 KO GCM exhibited less expansive myelin sheets when compared with $\mathrm{A} 2 \mathrm{~B} 5{ }^{+} \mathrm{OPCs}$ grown in WT GCM (Fig. $6 A, B$ ). The proportion of $\mathrm{A} 2 \mathrm{~B} 5{ }^{+}$progenitors following 1 week of differentiation in TIMP-1 KO GCM was $65 \%$ less than cultures grown in WT GCM (i.e., the number of A2B5 cells in TIMP-1 KO GCM was $35.5 \pm 10 \%$ of numbers grown in WT GCM) (Fig. 6A,B). The number of differentiated $\mathrm{O} 1^{+}$oligodendrocytes was also reduced in these $\mathrm{A} 2 \mathrm{~B} 5{ }^{+}$cultures grown in TIMP-1 KO GCM when compared with the proportion of mature $\mathrm{O}^{+}{ }^{+}$oligodendrocytes found in $\mathrm{A} 2 \mathrm{~B} 5{ }^{+}$cultures grown in WT GCM (i.e., the number of $\mathrm{O}^{+}$cells in TIMP-1 GCM was $26.1 \pm 7 \%$ of the number of cells differentiated in WT GCM) (Fig. 6A, $B$ ). ELISA assay for murine TIMP-1 determined that the concentration of TIMP-1 in the GCM from WT cultures was $\sim 7.5 \mathrm{ng} / \mathrm{ml}$, whereas TIMP-1 was not detected in TIMP-1 KO GCM $(0 \mathrm{ng} / \mathrm{ml})$. The concentration in the WT GCM was consistent with the concentration of rmTIMP-1 (10 ng/ml) found to induce astrocyte proliferation, increase $\mathrm{NG}_{2}{ }^{+}$cell numbers in the TIMP-1 KO neurosphere assay, and increase the numbers of mature $\mathrm{O} 1{ }^{+}$oligodendrocytes in the $\mathrm{A} 2 \mathrm{~B} 5{ }^{+}$cell cultures.

\section{Discussion}

We have identified a novel function for TIMP-1 in the regulation of OPC differentiation and astrocyte proliferation. Using purified OPC cultures, neurosphere assays, and primary glial cells, we have demonstrated that the effects of TIMP-1 can be direct, dose dependent, and MMP independent. In TIMP-1 KO mice, developmental myelination was markedly delayed and accompanied by a decrease in reactive astrocytes, suggesting that increased expression of TIMP-1 by astrocytes during early postnatal development may enhance the process of myelination in the CNS.

It is becoming increasingly evident that myelination is a multicellular effort requiring oligodendrocytes, neurons, and astrocytes for efficient myelin ensheathment of axons (Liedtke et al., 1996; Sorensen et al., 2008; Watkins et al., 2008). Astrocytes represent $\sim 50 \%$ of the cellular number in the adult CNS and are required for maintaining neuronal homeostasis by providing trophic and metabolic support (Smit et al., 2001; Ullian et al., 2001), as well as promoting neurogenesis (Song et al., 2002). More recently, the astrocyte has been shown to also play a critical role in efficient CNS myelination (Ishibashi et al., 2006; Sorensen et al., 2008; Watkins et al., 2008). Astrocytes secrete factors that promote OPC differentiation, proliferation, and survival (Gard et al., 1995; Butzkueven et al., 2002; Moore et al., 2011), in addition to promoting oligodendrocyte sheet extension ( $\mathrm{Oh}$ and Yong, 1996). Interestingly, astrocytes have been shown to proliferate during developmental myelination and following myelin injury (Tani et al., 1996; Pagenstecher et al., 1998), where they promote efficient myelination and remyelination, respectively (Franklin et al., 1991; Blakemore et al., 2003; Voskuhl et al., 2009). In myelinating CNS cocultures, astrocytes enhance the rate and extent of compact myelin formation, but are not essential for the generation of myelin. Similarly, coculture experiments lacking astrocytes reduce the numbers of myelinated axons and the extent of axon myelination (Watkins et al., 2008).

Our findings suggest that astrocytic TIMP-1 is a novel regulatory molecule for myelination in the developing and injured CNS. These findings also allude to interesting parallels in the TIMP-1 KO background regarding astrocytes and myelin. Specifically, we had previously reported that while there are no obvious myelin deficits in adult TIMP-1 KO mice, these mice exhibited poor remyelination following EAE (Crocker et al., 2006b). Moreover, myelin injury in adult TIMP-1 KO mice was also associated with reduced numbers of astrocytes (Crocker et al., 2006b). In the present study, we found that recombinant TIMP-1 protein stimulated the proliferation of cultured astrocytes, while the delay in CNS myelination in TIMP-1 KO mice was associated with reduced astrocytic activity in the developing CNS. This study provides new insight into a role for TIMP-1 as an autocrine and/or paracrine factor released by astrocytes that influences both OPCs and astrocytes. While TIMP-1 has been reported to be produced by several immune and CNS cell types (Toft-Hansen et al., 2004), its elevated expression by astrocytes both during development and following myelin injury provides further evidence that TIMP-1 plays a role in CNS myelination. The in vivo evidence that TIMP-1 KO mice have delayed CNS myelination accompanied by reduced activation of white matter astrocytes is consistent with the emerging model that astrocytes play a pivotal role in CNS myelination. Since complete myelination does eventually occur in TIMP-1 KO mice, our perspective is 
that heightened TIMP-1 expression during development, and following myelin injury in the adult, participates to enhance the overall effectiveness of CNS myelination and repair.

The significant decrease in $\operatorname{PDGF} \alpha \mathrm{R}^{+}$ OPCs in the white matter of P7 TIMP-1 $\mathrm{KO}$ mice prompted us to use ex vivo assays to determine whether exogenous TIMP-1 could directly influence OPC differentiation. We have now shown that TIMP-1 can directly promote OPC differentiation (Fig. 2), thus providing compelling new evidence that, in response to myelin injury, TIMP-1 can promote endogenous OPC differentiation and myelin repair independently of MMPs (Crocker et al., 2006b). Additional MMP-independent functions of TIMP family proteins have been previously reported. For example, TIMP-3 is a direct antagonist of the kinase-insert domain receptor and disrupts vascular endothelial growth factor (VEGF) signaling (Qi et al., 2003), while TIMP-2 can bind integrin $\alpha 3 \beta 1$ and block FGF-2 and VEGF signaling during angiogenesis (Seo et al., 2003, 2008). To our knowledge, this report is the first demonstration that TIMP-1 can act directly to enhance OPC differentiation. The exact mechanisms by which TIMP-1 elicits these MMP-independent actions is presently unresolved, although several possible mechanisms could be proposed. In a previous report, TIMP-1 has been shown to interact with a member of the tetraspanin family, CD63, on the surface of MCF10A breast epithelial cells (Jung et al., 2006). It is therefore plausible that a similar or analogous mechanism could also mediate the actions of TIMP-1 on OPCs and astrocytes during CNS myelination. Furthermore, it is also possible that TIMP-1 inhibits other enzymes independently of MMPs that are not blocked by GM6001. Alternatively, TIMP-1 may also interact with other cellular transduction signaling pathways, For instance, TIMP-3 has been reported to sensitize cells to FasL-induced cell death (Bond et al., 2002) and also stabilize the tumor necrosis factor receptor (Smith et al., 1997). Thus, a possible action of TIMP-1 may be to modulate a receptor-ligand interaction that leads to proliferation and/or differentiation of OPCs. Nevertheless, though the exact mechanism through which TIMP-1 elicits its functions in the context of OPCs and myelin has yet to be characterized, and will require further study, these present findings provide a new perspective for how TIMP-1 functions in the CNS.

This study describes a previously unidentified function of TIMP-1 to directly regulate oligodendrocyte differentiation. We

B the mean \pm SEM.
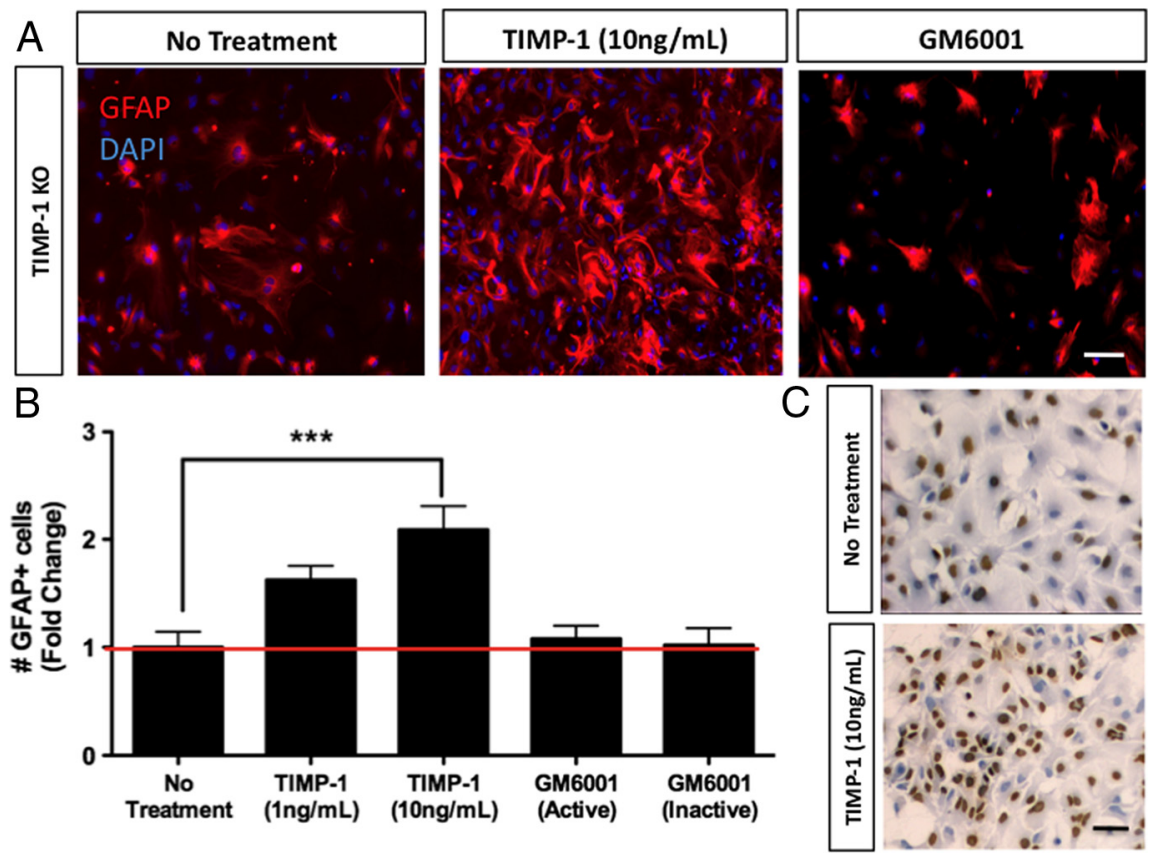

Figure 5. Recombinant TIMP-1 increases proliferation of astrocytes. $\boldsymbol{A}, \boldsymbol{B}$, Addition of rmTIMP-1 to primary glial cultures from TIMP-1 K0 mice resulted in a dose-dependent increase in astrocyte numbers, while treatment with GM6001 (active/inactive) did not alter astrocyte numbers ( $n=9 /$ group). C, Astrocytes incubated with BrdU followed by immunohistochemistry for BrdU show a significant increase in the numbers of $\mathrm{BrdU}^{+}$-labeled cells. Scale bars, $20 \mu \mathrm{m}$. ${ }^{* * *} p<0.001$. Error bars represent

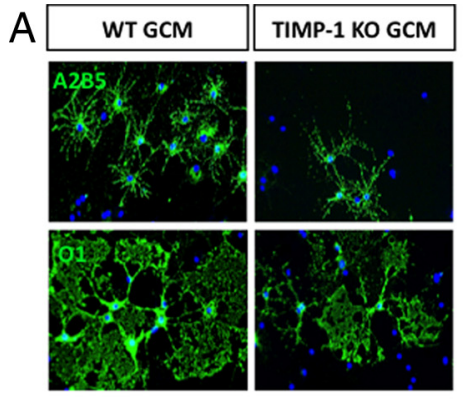

C

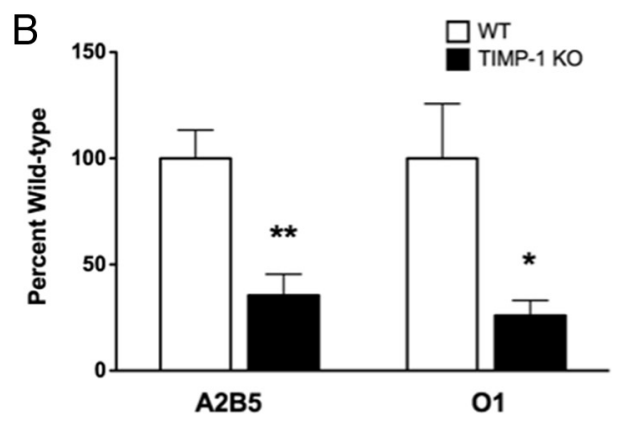

Figure 6. GCM derived from TIMP-1 KO mixed glial (astrocytes and microglia) cultures poorly supports primary oligodendrocyte growth and differentiation. $A$, Primary oligodendrocyte precursor cells $\left(\mathrm{A} 2 \mathrm{~B} 5{ }^{+}\right)$were split and grown in either conditioned media collected from either WT C57BL/6 or TIMP-1 KO primary glial cultures. Immunocytochemistry for A2B5 and 01 following $5 \mathrm{~d}$ of culture revealed fewer $\mathrm{A}_{2} \mathrm{BS}^{+}$cells, while $01^{+}$cells exhibited a stunted morphology with smaller membranous fans of prospective myelin. B, Quantification of $\mathrm{A}_{2} \mathrm{BS}^{+}$and $01^{+}$cells confirmed 65 and $74 \%$ decrease, respectively, in the numbers of cells grown in GCM derived from TIMP- $1 \mathrm{~K} 0$ mice. Error bars represent the mean \pm SEM. ${ }^{* *} p<0.01,{ }^{*} p<0.05$. C, Hypothesized model of TIMP- 1 in the regulation of astrocyte functions during oligodendrocyte differentiation and CNS myelination. Our data indicate that astrocyte production of TIMP-1 functions directly to promote OPC differentiation. Coincidently, TIMP-1 also signals as an autocrine or paracrine factor on astrocytes that may too support OPC differentiation. An important effect of astrocytic TIMP-1 expression therefore is to enhance CNS myelination.

have also determined that TIMP-1 may enhance myelination by functioning in an autocrine, or paracrine, manner to influence astrocyte reactivity during CNS myelination. Together, these findings support a function for TIMP-1 to directly promote OPC differentiation while also increasing astrocyte support for OPCs 
and CNS myelination (Fig. 6C). In the healthy adult CNS, expression of TIMP-1 is very low, yet is highly expressed following inflammatory brain injury and in diseases such as acute demyelinating encephalomyelitis (ADEM) (Ichiyama et al., 2006), cerebral ischemia, Parkinson's disease, Alzheimer's disease, and amyotrophic lateral sclerosis (for review, see Crocker et al., 2004). The revised model for a role of TIMP-1 during demyelinating diseases may be linked to promoting remyelination. For instance, in ADEM, an acute demyelinating disease of the CNS that spontaneously resolves, TIMP-1 levels were markedly higher than those in controls (Ichiyama et al., 2006). In contrast, in multiple sclerosis (MS), a chronic demyelinating condition characterized by minimal myelin repair, expression of TIMP-1 did not differ from healthy age-matched controls (Avolio et al., 2003; Waubant et al., 2003). We therefore hypothesize that in the diseased adult brain, increased TIMP-1 expression may contribute to remyelination and/or myelin recovery. Indeed, this idea is now supported by both our previous finding that adult TIMP-1 KO mice exhibited poor myelin recovery in EAE (Crocker et al., 2006b) and a recent study by Althoff et al. (2010), which demonstrated that transgenic expression of TIMP-1 by astrocytes had a mitigating effect on the clinical development of EAE and myelin pathology. Collectively with the present study, we hypothesize that inadequate expression of TIMP-1 in MS contributes to myelin pathology by less efficient myelin repair and development of chronic myelin pathology. This emerging role of TIMP-1 in CNS myelination would also suggest that strategies used to enhance TIMP-1 expression in response to CNS injury might represent a novel therapeutic strategy to promote endogenous remyelination.

\section{References}

Althoff GE, Wolfer DP, Timmesfeld N, Kanzler B, Schrewe H, Pagenstecher A (2010) Long-term expression of tissue-inhibitor of matrix metalloproteinase-1 in the murine central nervous system does not alter the morphological and behavioral phenotype but alleviates the course of experimental allergic encephalomyelitis. Am J Pathol 177:840-853.

Avolio C, Ruggieri M, Giuliani F, Liuzzi GM, Leante R, Riccio P, Livrea P, Trojano M (2003) Serum MMP-2 and MMP-9 are elevated in different multiple sclerosis subtypes. J Neuroimmunol 136:46-53.

Baracskay KL, Kidd GJ, Miller RH, Trapp BD (2007) NG2-positive cells generate A2B5-positive oligodendrocyte precursor cells. Glia 55:1001-1010.

Barres BA, Hart IK, Coles HS, Burne JF, Voyvodic JT, Richardson WD, Raff MC (1992) Cell death and control of cell survival in the oligodendrocyte lineage. Cell 70:31-46.

Blakemore WF, Gilson JM, Crang AJ (2003) The presence of astrocytes in areas of demyelination influences remyelination following transplantation of oligodendrocyte progenitors. Exp Neurol 184:955-963.

Bond M, Murphy G, Bennett MR, Newby AC, Baker AH (2002) Tissue inhibitor of metalloproteinase- 3 induces a Fas-associated death domaindependent type II apoptotic pathway. J Biol Chem 277:13787-13795.

Buttery PC, ffrench-Constant C (1999) Laminin-2/integrin interactions enhance myelin membrane formation by oligodendrocytes. Mol Cell Neurosci 14:199-212.

Butzkueven H, Zhang JG, Soilu-Hanninen M, Hochrein H, Chionh F, Shipham KA, Emery B, Turnley AM, Petratos S, Ernst M, Bartlett PF, Kilpatrick TJ (2002) LIF receptor signaling limits immune-mediated demyelination by enhancing oligodendrocyte survival. Nat Med 8:613-619.

Chesler L, Golde DW, Bersch N, Johnson MD (1995) Metalloproteinase inhibition and erythroid potentiation are independent activities of tissue inhibitor of metalloproteinases-1. Blood 86:4506-4515.

Crocker SJ, Pagenstecher A, Campbell IL (2004) The TIMPs tango with MMPs and more in the central nervous system. J Neurosci Res 75:1-11.

Crocker SJ, Milner R, Pham-Mitchell N, Campbell IL (2006a) Cell and agonist-specific regulation of genes for matrix metalloproteinases and their tissue inhibitors by primary glial cells. J Neurochem 98:812-823.

Crocker SJ, Whitmire JK, Frausto RF, Chertboonmuang P, Soloway PD,
Whitton JL, Campbell IL (2006b) Persistent macrophage/microglial activation and myelin disruption after experimental autoimmune encephalomyelitis in tissue inhibitor of metalloproteinase-1-deficient mice. Am J Pathol 169:2104-2116.

Crocker SJ, Frausto RF, Whitmire JK, Benning N, Milner R, Whitton JL (2007) Amelioration of coxsackievirus B3-mediated myocarditis by inhibition of tissue inhibitors of matrix metalloproteinase-1. Am J Pathol 171:1762-1773.

Crocker SJ, Frausto RF, Whitton JL, Milner R (2008) A novel method to establish microglia-free astrocyte cultures: comparison of matrix metalloproteinase expression profiles in pure cultures of astrocytes and microglia. Glia 56:1187-1198.

Fok-Seang J, Miller RH (1992) Astrocyte precursors in neonatal rat spinal cord cultures. J Neurosci 12:2751-2764.

Foran DR, Peterson AC (1992) Myelin acquisition in the central nervous system of the mouse revealed by an MBP-Lac Z transgene. J Neurosci 12:4890-4897.

Franklin RJ, Crang AJ, Blakemore WF (1991) Transplanted type-1 astrocytes facilitate repair of demyelinating lesions by host oligodendrocytes in adult rat spinal cord. J Neurocytol 20:420-430.

Gard AL, Burrell MR, Pfeiffer SE, Rudge JS, Williams WC 2nd (1995) Astroglial control of oligodendrocyte survival mediated by PDGF and leukemia inhibitory factor-like protein. Development 121:2187-2197.

Hernández-Guillamon M, Delgado P, Ortega L, Pares M, Rosell A, GarcíaBonilla L, Fernández-Cadenas I, Borrell-Pagès $\mathrm{M}$, Boada $\mathrm{M}$, Montaner J (2009) Neuronal TIMP-1 release accompanies astrocytic MMP-9 secretion and enhances astrocyte proliferation induced by beta-amyloid 25-35 fragment. J Neurosci Res 87:2115-2125.

Ichiyama T, Kajimoto M, Suenaga N, Maeba S, Matsubara T, Furukawa S (2006) Serum levels of matrix metalloproteinase-9 and its tissue inhibitor (TIMP-1) in acute disseminated encephalomyelitis. J Neuroimmunol 172:182-186.

Ishibashi T, Dakin KA, Stevens B, Lee PR, Kozlov SV, Stewart CL, Fields RD (2006) Astrocytes promote myelination in response to electrical impulses. Neuron 49:823-832.

Jourquin J, Tremblay E, Bernard A, Charton G, Chaillan FA, Marchetti E, Roman FS, Soloway PD, Dive V, Yiotakis A, Khrestchatisky M, Rivera S (2005) Tissue inhibitor of metalloproteinases-1 (TIMP-1) modulates neuronal death, axonal plasticity, and learning and memory. Eur J Neurosci 22:2569-2578.

Jung KK, Liu XW, Chirco R, Fridman R, Kim HR (2006) Identification of CD63 as a tissue inhibitor of metalloproteinase-1 interacting cell surface protein. EMBO J 25:3934-3942.

Kearns SM, Laywell ED, Kukekov VK, Steindler DA (2003) Extracellular matrix effects on neurosphere cell motility. Exp Neurol 182:240-244.

Komitova M, Zhu X, Serwanski DR, Nishiyama A (2009) NG2 cells are distinct from neurogenic cells in the postnatal mouse subventricular zone. J Comp Neurol 512:702-716.

Lee MM, Yoon BJ, Osiewicz K, Preston M, Bundy B, van Heeckeren AM, Werb Z, Soloway PD (2005) Tissue inhibitor of metalloproteinase 1 regulates resistance to infection. Infect Immun 73:661-665.

Liedtke W, Edelmann W, Bieri PL, Chiu FC, Cowan NJ, Kucherlapati R, Raine CS (1996) GFAP is necessary for the integrity of CNS white matter architecture and long-term maintenance of myelination. Neuron 17:607-615.

Moore CS, Abdullah SL, Brown A, Arulpragasam A, Crocker SJ (2011) How factors secreted from astrocytes impact myelin repair. J Neurosci Res 89:13-21.

Murate T, Yamashita K, Ohashi H, Kagami Y, Tsushita K, Kinoshita T, Hotta T, Saito H, Yoshida S, Mori KJ (1993) Erythroid potentiating activity of tissue inhibitor of metalloproteinases on the differentiation of erythropoietinresponsive mouse erythroleukemia cell line, ELM-I-1-3, is closely related to its cell growth potentiating activity. Exp Hematol 21:169-176.

Nishiyama A, Komitova M, Suzuki R, Zhu X (2009) Polydendrocytes (NG2 cells): multifunctional cells with lineage plasticity. Nat Rev Neurosci 10:9-22.

Noll E, Miller RH (1994) Regulation of oligodendrocyte differentiation: a role for retinoic acid in the spinal cord. Development 120:649-660.

Nygårdas PT, Hinkkanen AE (2002) Up-regulation of MMP-8 and MMP-9 activity in the BALB/c mouse spinal cord correlates with the severity of experimental autoimmune encephalomyelitis. Clin Exp Immunol 128:245-254. 
Oh LY, Yong VW (1996) Astrocytes promote process outgrowth by adult human oligodendrocytes in vitro through interaction between bFGF and astrocyte extracellular matrix. Glia 17:237-253.

Pagenstecher A, Stalder AK, Kincaid CL, Shapiro SD, Campbell IL (1998) Differential expression of matrix metalloproteinase and tissue inhibitor of matrix metalloproteinase genes in the mouse central nervous system in normal and inflammatory states. Am J Pathol 152:729-741.

Qi JH, Ebrahem Q, Moore N, Murphy G, Claesson-Welsh L, Bond M, Baker A, Anand-Apte B (2003) A novel function for tissue inhibitor of metalloproteinases-3 (TIMP3): inhibition of angiogenesis by blockage of VEGF binding to VEGF receptor-2. Nat Med 9:407-415.

Seo DW, Li H, Guedez L, Wingfield PT, Diaz T, Salloum R, Wei BY, StetlerStevenson WG (2003) TIMP-2 mediated inhibition of angiogenesis: an MMP-independent mechanism. Cell 114:171-180.

Seo DW, Kim SH, Eom SH, Yoon HJ, Cho YR, Kim PH, Kim YK, Han JW, Diaz T, Wei BY, Stetler-Stevenson WG (2008) TIMP-2 disrupts FGF-2induced downstream signaling pathways. Microvasc Res 76:145-151.

Smit AB, Syed NI, Schaap D, van Minnen J, Klumperman J, Kits KS, Lodder $\mathrm{H}$, van der Schors RC, van Elk R, Sorgedrager B, Brejc K, Sixma TK, Geraerts WP (2001) A glia-derived acetylcholine-binding protein that modulates synaptic transmission. Nature 411:261-268.

Smith MR, Kung H, Durum SK, Colburn NH, Sun Y (1997) TIMP-3 induces cell death by stabilizing TNF-alpha receptors on the surface of human colon carcinoma cells. Cytokine 9:770-780.

Song H, Stevens CF, Gage FH (2002) Astroglia induce neurogenesis from adult neural stem cells. Nature 417:39-44.

Sorensen A, Moffat K, Thomson C, Barnett SC (2008) Astrocytes, but not olfactory ensheathing cells or Schwann cells, promote myelination of CNS axons in vitro. Glia 56:750-763.

Stetler-Stevenson WG (2008) Tissue inhibitors of metalloproteinases in cell signaling: metalloproteinase-independent biological activities. Sci Signal 1:re6.

Tan HK, Heywood D, Ralph GS, Bienemann A, Baker AH, Uney JB (2003) Tissue inhibitor of metalloproteinase 1 inhibits excitotoxic cell death in neurons. Mol Cell Neurosci 22:98-106.

Tani M, Glabinski AR, Tuohy VK, Stoler MH, Estes ML, Ransohoff RM (1996) In situ hybridization analysis of glial fibrillary acidic protein mRNA reveals evidence of biphasic astrocyte activation during acute experimental autoimmune encephalomyelitis. Am J Pathol 148:889-896.
Toft-Hansen H, Nuttall RK, Edwards DR, Owens T (2004) Key metalloproteinases are expressed by specific cell types in experimental autoimmune encephalomyelitis. J Immunol 173:5209-5218.

Tsagaraki I, Tsilibary EC, Tzinia AK (2010) TIMP-1 interaction with alphavbeta3 integrin confers resistance to human osteosarcoma cell line MG-63 against TNF-alpha-induced apoptosis. Cell Tissue Res 342:87-96.

Ullian EM, Sapperstein SK, Christopherson KS, Barres BA (2001) Control of synapse number by glia. Science 291:657-661.

Ulrich R, Gerhauser I, Seeliger F, Baumgärtner W, Alldinger S (2005) Matrix metalloproteinases and their inhibitors in the developing mouse brain and spinal cord: a reverse transcription quantitative polymerase chain reaction study. Dev Neurosci 27:408-418.

Ulrich R, Baumgärtner W, Gerhauser I, Seeliger F, Haist V, Deschl U, Alldinger S (2006) MMP-12, MMP-3, and TIMP-1 are markedly upregulated in chronic demyelinating theiler murine encephalomyelitis. J Neuropathol Exp Neurol 65:783-793.

Voskuhl RR, Peterson RS, Song B, Ao Y, Morales LB, Tiwari-Woodruff S, Sofroniew MV (2009) Reactive astrocytes form scar-like perivascular barriers to leukocytes during adaptive immune inflammation of the CNS. J Neurosci 29:11511-11522.

Watkins TA, Emery B, Mulinyawe S, Barres BA (2008) Distinct stages of myelination regulated by gamma-secretase and astrocytes in a rapidly myelinating CNS coculture system. Neuron 60:555-569.

Waubant E, Goodkin D, Bostrom A, Bacchetti P, Hietpas J, Lindberg R, Leppert D (2003) IFNbeta lowers MMP-9/TIMP-1 ratio, which predicts new enhancing lesions in patients with SPMS. Neurology 60:52-57.

Woolley DE, Roberts DR, Evanson JM (1975) Inhibition of human collagenase activity by a small molecular weight serum protein. Biochem Biophys Res Commun 66:747-754.

Young DA, Phillips BW, Lundy C, Nuttall RK, Hogan A, Schultz GA, Leco KJ, Clark IM, Edwards DR (2002a) Identification of an initiator-like element essential for the expression of the tissue inhibitor of metalloproteinases-4 (Timp-4) gene. Biochem J 364:89-99.

Young KA, Hennebold JD, Stouffer RL (2002b) Dynamic expression of mRNAs and proteins for matrix metalloproteinases and their tissue inhibitors in the primate corpus luteum during the menstrual cycle. Mol Hum Reprod 8:833-840. 